\title{
Source shape and data analysis procedure effects on hydraulic conductivity of a sandy-loam soil determined by ponding infiltration runs
}

\author{
Vincenzo Bagarello, Andrea De Santis, Giuseppe Giordano, Massimo Iovino \\ Department of Agricultural and Forestry Sciences, University of Palermo, Italy
}

\begin{abstract}
Performing ponding infiltration runs with non-circular sources could represent a good means to sample completely an area of interest. Regardless of the shape of the source, predicting the expected reliability of the collected data by infiltrometers should facilitate soil hydraulic characterisation and also allow a more conscious use of the field data. The influence of the shape of the infiltration source (i.e., circular or square) and the analysis procedure of the steady-state infiltration data on the saturated hydraulic conductivity, $K_{s}$, of a sandy-loam soil was tested in this investigation. Circular and square surfaces sampled with the pressure infiltrometer (PI) yielded similar estimates of $K_{s}$ (i.e., differing by a factor of 1.05-1.16, depending on the calculation method) when an equivalent radius was considered to geometrically describe the square source. With the simplified falling head (SFH) technique, the shape of the source was irrelevant (i.e., circular and square sources yielding $K_{S}$ values that differed by a factor of 1.19), as theoretically expected. For the steady-state PI experiment, the twoponding depth approach yielded two times smaller $K_{S}$ values than the one-ponding depth (OPD) approach, probably due to lower steady-state flow rates than those expected for the second phase of the two-level run. The conclusions were that: i) simple infiltrometer experiments (PI, SFH) can be carried out with square sources; and ii) the simplest PI run (OPD approach) is expected to yield the most reliable predictions of $K_{S}$. Sampling other soils is advisable in an attempt to make these conclusions of general validity.
\end{abstract}

Correspondence: Vincenzo Bagarello, Department of Agricultural and Forestry Sciences, University of Palermo, viale delle Scienze, 90128 Palermo, Italy.

E-mail: vincenzo.bagarello@unipa.it

Key words: Pressure infiltrometer; saturated soil hydraulic conductivity; infiltration source shape; simplified falling head technique.

Received for publication: 2 September 2016.

Accepted for publication: 21 December 2016.

CC Copyright V. Bagarello et al., 2017

Licensee PAGEPress, Italy

Journal of Agricultural Engineering 2017; XLVIII:597

doi:10.4081/jae.2017.597

This article is distributed under the terms of the Creative Commons Attribution Noncommercial License (by-nc 4.0) which permits any noncommercial use, distribution, and reproduction in any medium, provided the original author(s) and source are credited.

\section{Introduction}

Measuring saturated soil hydraulic conductivity, $K_{S}$, directly in the field is recommended for interpreting and modelling soil hydrologic processes since disturbance of the sampled soil volume is minimised and its functional connection with the surrounding soil is maintained (Bouma, 1982). Due to the practical difficulties of fieldwork, reliable data should be collected with a reasonably simple and rapid experiment.

The single-ring pressure infiltrometer (PI) (Reynolds and Elrick, 1990) is a simple device that has frequently been applied in the field during the past 20 years (Vauclin et al., 1994; Ciollaro and Lamaddalena, 1998; Bagarello and Iovino, 1999; AnguloJaramillo et al., 2000; Bagarello et al., 2000; Reynolds et al., 2000; Mertens et al., 2002; Bagarello and Sgroi, 2004; Gómez et al., 2005; Verbist et al., 2009, 2010; Bagarello et al., 2013b; Verbist et al., 2013; Bagarello et al., 2014a; Angulo-Jaramillo et al., 2016). A constant hydraulic head is established within a ring inserted to a short depth into the soil, and three-dimensional flow rate into the soil is monitored until near steady-state conditions have been reached. The steady-state methods developed by Reynolds and Elrick (1990), and particularly the one-ponding depth (OPD) and two-ponding depth (TPD) approaches, are the most commonly applied methods to analyse the PI data, although a variety of alternative methods have been considered in different investigations (Table 1). The OPD approach implies establishing a single depth of ponding on the infiltration surface but it needs an independent estimate of the so-called $\alpha^{*}$ parameter, that represents the ratio of gravity to capillary forces during the infiltration process (Reynolds and Elrick, 2002a). The TPD approach yields a simultaneous estimate of $K_{s}$ and $\alpha^{*}$ but the experiment is more complicated since two depths of ponding have to be established in succession on the infiltration surface. The simplified falling head (SFH) technique is another ponding infiltration technique (Bagarello et al., 2004). In this case, an estimate of $K_{s}$ is obtained by a one-dimensional, transient, falling-head infiltration process (Bagarello and Sgroi, 2007; Bagarello et al., 2010; Agnese et al., 2011; Bagarello et al., 2013a). An independent estimate of $\alpha^{*}$ is also necessary to analyse the infiltration data collected by the SFH run. For both infiltration techniques, there are experimental and/or analytical issues still needing clarifications and developments.

All available methods to analyse the PI data assume that the source is circular but using non-circular sources could be advisable in particular circumstances. For example, a square infiltrometer could allow, at least in theory, to sample completely an area of interest, which is less practical with a circular source. Therefore, the use of a ring infiltrometer precludes the possibility to uniformly collect data although intensively sampling soil represents an important step toward an improved interpretation and simulation of hydrological processes at the field scale (Gómez et al., 2005; Bagarello et al., 2013a). In principle, a square infiltrometer allows not to lose some possibly important information that is 
unavoidably lost with a ring infiltrometer. Employing a square infiltrometer raises a problem in the calculations of $K_{S}$ since the developed equations include the ring radius that has to be replaced by a suitable alternative quantity if a square source is being used. Gómez et al. (2005) used a square infiltrometer and determined $K_{S}$ by assuming that the ring radius coincided with the side length of the infiltrometer. Using numerically simulated data, Bagarello et al. (2016) suggested that steady-state infiltration data collected with a square infiltrometer can be analysed with the model by Reynolds and Elrick (1990), assuming that infiltration occurs through a circular source having the same area of the square infiltrometer, which maintains congruence in flux density. However, field comparisons between PI data obtained with circular and square sources are still lacking. The shape of the source does not have any theoretical influence on the estimation of $K_{S}$ by the SFH technique since the infiltration process is one-dimensional in this case. Therefore, sources of different shape (e.g., circular, square) are expected to yield similar results. However, rings are commonly used even with the SFH technique and a field comparison between alternative shapes of the source has never been carried out.

According to the existing literature, the PI technique is expected to yield more reliable estimates of $K_{S}$ than $\alpha^{*}$ (Reynolds and Elrick, 1990; Mertens et al., 2002). Notwithstanding this, a plausible $\alpha^{*}$ value, i.e., falling within the realistic range of 1 to $100 \mathrm{~m}^{-1}$, together with positive estimates of both $K_{s}$ and $\alpha^{*}$, should be indicative of reliable TPD calculations on the basis of the existing guidelines (Reynolds and Elrick, 2002b). This criterion has much interest from a practical point of view since it seems to suggest that the calculated $K_{S}$ and $\alpha^{*}$ values contain the necessary information to discriminate between reliable and unreliable data. To our knowledge, however, this reliability criterion has never been checked in the field.

The general objective of this investigation was to improve our ability to use ponding infiltration runs for field determination of saturated hydraulic conductivity, $K_{S}$, of a sandy-loam soil. The specific objectives were to: i) establish a comparison between circular and square sources with reference to the $K_{S}$ values obtained by both the pressure infiltrometer and the simplified falling head technique; and ii) test if the reliability criterion developed for the pressure infiltrometer and the two-ponding depth approach is enough to obtain good quality data.

\section{Theory}

\section{Pressure infiltrometer}

Steady, ponded infiltration from within a single ring into rigid, homogeneous, isotropic, uniformly unsaturated soil can be approximated by the following analytical expression for steady-state infiltration fluxes (Reynolds and Elrick, 1990):

$$
Q_{s}=\frac{r}{G}\left(K_{s} H+\phi_{m}\right)+\pi r^{2} K_{s}
$$

where $Q_{s}\left(\mathrm{~L}^{3} \mathrm{~T}^{-1}\right)$ is the steady-state flow rate, $r(\mathrm{~L})$ is the ring radius, $G$ is a dimensionless shape parameter, $K_{S}\left(\mathrm{~L} \mathrm{~T}^{-1}\right)$ is the saturated soil hydraulic conductivity, $H(\mathrm{~L})$ is the steady depth of ponding in the ring, and $\phi_{m}\left(\mathrm{~L}^{2} \mathrm{~T}^{-1}\right)$ is the matric flux potential. For practical purposes, the following estimate of $G$ can be used (Reynolds and Elrick, 1990):

$$
G=0.316 \frac{d}{r}+0.184
$$

where $d(\mathrm{~L})$ is the depth of ring insertion. With the TPD approach,

\begin{tabular}{|c|c|}
\hline Reference & Applied methods \\
\hline Vauclin et al. (1994) & TPD. OPD. Analysis of early-time transient flow \\
\hline Ciollaro and Lamaddalena (1998) & OPD (steady-state flow rate estimated by fitting the modified Kostiakov equation to the infiltration data) \\
\hline Bagarello and Iovino (1999) & OPD. Analysis of early-time transient flow \\
\hline Bagarello et al. (2000) & TPD. OPD \\
\hline Reynolds et al. (2000) & TPD. OPD \\
\hline Mertens et al. (2002) & TPD. Inverse optimisation technique (estimates of $\mathrm{K}_{\mathrm{S}}$ for each sampling point and one overall field $\alpha^{*}$ parameter) \\
\hline Bagarello and Sgroi (2004) & OPD \\
\hline Gómez et al. (2005) & Method 2 by Wu et al. (1999) \\
\hline Bagarello and Sgroi (2007) & OPD \\
\hline Bagarello et al. (2009a) & TPD. Method 1 by Wu et al. (1999) \\
\hline Verbist et al. (2009) & OPD. Method 1 by Wu et al. (1999) \\
\hline Verbist et al. (2010) & $\begin{array}{l}\text { OPD. Methods } 1 \text { and } 2 \text { by Wu et al. (1999). Assumption that } \mathrm{K}_{\mathrm{s}} \text { coincides with the steady-state infiltration rate. } \\
\text { Equation by Youngs (1987) [Eq. (5) in Verbist et al., 2010]. } \\
\text { Fitting alternative infiltration models to the data to obtain an estimate of } \mathrm{K}_{\mathrm{S}}\end{array}$ \\
\hline Bagarello et al. (2013b) & TPD \\
\hline Bagarello et al. (2014a) & TPD. OPD \\
\hline Verbist et al. (2013) & Method 2 by Wu et al. (1999) \\
\hline Alagna et al. (2016b) & TPD \\
\hline
\end{tabular}

Table 1. Applied methods to analyse the infiltration data collected by the pressure infiltrometer. 
$K_{s}$ and $\phi_{m}$ are given by (Reynolds and Elrick, 1990):

$$
\begin{aligned}
K_{s} & =\frac{G}{r}\left(\frac{Q_{s 2}-Q_{s 1}}{H_{2}-H_{1}}\right) \\
\phi_{m} & =\frac{G}{r}\left(\frac{H_{2} Q_{s 1}-H_{1} Q_{s 2}}{H_{2}-H_{1}}-\pi r G \frac{Q_{s 2}-Q_{s 1}}{H_{2}-H_{1}}\right)
\end{aligned}
$$

where $H_{1}$ and $H_{2}(\mathrm{~L})$ are the steady depths of ponding $\left(H_{2}>H_{1}\right)$ and $Q_{s 1}$ and $Q_{s 2}\left(\mathrm{~L}^{3} \mathrm{~T}^{-1}\right)$ are the corresponding steady flow rates. Then, the so-called $\alpha^{*}$ parameter $\left(\mathrm{L}^{-1}\right)$ can be calculated as:

$$
\alpha^{*}=\frac{K_{s}}{\phi_{m}}
$$

The OPD approach implies measurement of a single $Q_{s}$ value corresponding to an established ponding depth of water, $H$, and the estimation of $\alpha^{*}$ on the basis of the visually determined soil textural/structural characteristics (Elrick and Reynolds, 1992; Reynolds and Elrick, 1990; Reynolds et al., 2002). The following relationship is then used to obtain $K_{s}$ :

$$
K_{s}=\frac{\alpha^{*} G Q_{s}}{r\left(\alpha^{*} H+1\right)+G \alpha^{*} \pi r^{2}}
$$

The $\alpha^{*}$ parameter generally varies from 1 to $50 \mathrm{~m}^{-1}$ because of the direct and partially compensatory relationship between $K_{S}$ and $\phi_{m}$ that instead can individually range over many orders of magnitude (Reynolds and Elrick, 2002a). The reduced variability of $\alpha^{*}$ and its connection to soil texture and structure make it a useful parameter in simplified single-head analyses for estimation of $K_{s}$.

According to Bagarello et al. (2016), $K_{S}$ can be determined by using the steady-state infiltration data collected by a square infiltrometer and the relationships by Reynolds and Elrick (1990) because it is possible to assume that infiltration occurred through a circular surface having the same area of the surface sampled by the square infiltrometer. In other terms, the equivalent radius, $r_{e q}(\mathrm{~L})$, that replaces $r$ in Eq. (1) and the subsequent equations when steady-state flow rates are obtained from a square source, is:

$$
r_{e q}=\frac{l}{\sqrt{\pi}}
$$

where $l(\mathrm{~L})$ is the side length of the square infiltrometer. In the analysis by Gómez et al. (2005), also using a square infiltrometer, the following assumption was made:

$$
r_{e q}=l
$$

\section{Simplified falling head technique}

The SFH technique (Bagarello et al., 2004) consists of quickly pouring a known volume of water, $V\left(\mathrm{~L}^{3}\right)$, on the soil, generally confined by a ring inserted a fixed distance, $d(\mathrm{~L})$, into the soil, and in measuring the time, $t_{a}(\mathrm{~T})$, from the application of water to the instant in which the surface area, $A\left(\mathrm{~L}^{2}\right)$, is no longer covered by water. To determine $K_{S}$, the following equation, based on the analysis by Philip (1992) for falling-head one-dimensional cumulative infiltration, is applied:

$$
K_{s}=\frac{\Delta \theta}{(1-\Delta \theta)_{a}}\left[\frac{D}{\Delta \theta}-\frac{\left(D+\frac{1}{\alpha^{*}}\right)}{1-\Delta \theta} \ln \left(1+\frac{(1-\Delta \theta) D}{\Delta \theta\left(D+\frac{1}{\alpha^{*}}\right)}\right)\right]
$$

where $\Delta \theta\left(\mathrm{L}^{3} \mathrm{~L}^{-3}\right)$ is the difference between the saturated $\left(\theta_{s}\right)$ and the initial $\left(\theta_{i}\right)$ volumetric soil water content and $D=V / A(\mathrm{~L})$ is the depth of water corresponding to $V$. Knowledge of $\Delta \theta$ and $d$ allows to determine the volume of voids within the soil volume confined by the ring. A volume of water less than or equal to the volume of voids has to be used to assure one-dimensional flow during the experiment. Since Eq. (8) includes gravity, the only time limitation will occur if the wetting front emerges from the bottom of the ring and three-dimensional flow commences.

\section{Materials and methods}

\section{Field site}

The field experiment was carried out at the so-called AR site that was established at the Department of Agricultural and Forestry Sciences of Palermo University (Italy) (Table 2). A $400 \mathrm{~m}^{2}$ flat area of a citrus orchard, with trees spaced $4 \times 4 \mathrm{~m}$ apart, was selected. The soil (Typic Rhodoxeralf) had a relatively high sand and gravel content. The soil texture of the upper part of the profile, $0.1 \mathrm{~m}$ thick, was sandy-loam according to the United States Department of Agriculture (USDA) classification (Alagna et al., 2016a).

\section{Pressure infiltrometer experiment}

A PI infiltration test was conducted in 39 randomly chosen locations within the experimental area. An infiltrometer consisting of a Mariotte reservoir $1.0 \mathrm{~m}$ high with a volume of approximately $11 \mathrm{~L}$ was used. All runs were carried out at the soil surface, after removing the first few centimetres of soil. A ring with an inner

Table 2. General information on the sampled field site and the experiments with both the pressure infiltrometer and the simplified falling head technique.

\begin{tabular}{lc} 
Characteristic factor & Values or class \\
Coordinates & $38^{\circ} 06^{\prime} 24^{\prime \prime}$ N, $13^{\circ} 21^{\prime} 06^{\prime \prime} \mathrm{E}$ \\
Size of the experimental area (m2) & 400 \\
\hline Clay (\%) & 17.6 \\
Silt (\%) (USDA classification) & 29.8 \\
\hline Sand (\%) & 52.6 \\
Gravel (\%) & 13.0 \\
\hline Soil textural class & Sandy-loam \\
USDA pedological classification & Typic Rhodoxeralf \\
\hline Experimental period for the two-level (PI) runs & Jan-Jul 2015 \\
Total duration of a two-level run (min-max) (min) & $150-170$ \\
\hline Experimental period for the falling head (SFH) runs & Apr-May 2016 \\
Total duration of a falling head run (min-max) (min) & $1-3$ \\
\hline USDA, United States Department of Agriculture; PI, pressure infiltrometer; SFH, simplified falling head.
\end{tabular}


radius $r=0.075 \mathrm{~m}$ was inserted to a depth $d=0.03 \mathrm{~m}$ at 19 locations whereas a square box having a side length $l=0.133 \mathrm{~m}$ with opened top and bottom ends was inserted to the same depth at other 20 locations, so that the infiltration surface was of $0.0177 \mathrm{~m}^{2}$ with both sources. Ring and square box insertion was conducted by gently using a rubber hammer and ensuring that the upper rim of the ring remained horizontal during insertion. A pile driver could also be used for a vertical insertion of the ring. A constant depth of ponding, $H_{1}=0.053 \mathrm{~m}$, was established on the soil surface and flow rate was monitored to detect near steady-state conditions. A constant depth of ponding, $H_{2}=0.11 \mathrm{~m}$, was then established and flow rate was monitored until another quasi steady-state condition was reached. The total duration of the run varied between 150 and 170 min, depending on the sampling point (Table 2). The rate of fall of the water level in the infiltrometer reservoir was monitored at 0.5 to 2 min time intervals. In several cases, high infiltration rates were observed and the water reservoir emptied before concluding the test. Refilling of the reservoir and changing the ponded depth of water from $H_{1}$ to $H_{2}$ were conducted by maintaining ponded conditions on the soil surface confined by the ring to avoid air entrapment in the sampled soil volume (Reynolds, 1993). Due to the refilling procedure, apparent steady-state flow rates $\left(Q_{s 1}\right.$ and $\left.Q_{s 2}\right)$ corresponding to the two applied $H$ levels $\left(H_{1}\right.$ and $\left.H_{2}\right)$ were estimated from the flow rate versus time plot. In general, a run with the ring and another run with the square box were carried out on a single day to reduce the risk to detect differences between the two sources that could be in reality expressive of differences in initial soil conditions. At an intermediate distance between the two sources, two undisturbed soil cores $(0.05 \mathrm{~m}$ diam. by $0.05 \mathrm{~m}$ high) were collected at a depth of 0 to $0.05 \mathrm{~m}$ and 0.05 to $0.10 \mathrm{~m}$, respectively, before the PI test. These cores were used to determine the bulk density, $\rho_{b}\left(\mathrm{Mg} \mathrm{m}^{-3}\right)$, and the initial volumetric soil water content, $\theta_{i}\left(\mathrm{~m}^{3} \mathrm{~m}^{-3}\right)$, that were averaged over the two sampled depths. The experiments were carried out in a period of seven months (Table 2), to explore a wide range of initial soil moisture condi- tions. For each two-level infiltration run, $K_{S}$ and $\alpha^{*}$ were simultaneously calculated by Eqs. (3) and (4), with Eqs. (6) or (7) used in the case of a square source, and a dataset was developed for each source (circular, square). In particular, only the two-level runs simultaneously yielding positive results for the two variables and $\alpha^{*}$ values ranging from $1 \mathrm{~m}^{-1}$ to $100 \mathrm{~m}^{-1}$ were included in the dataset (scenario no. 1, TPD), according to Reynolds and Elrick (2002b). Two additional scenarios were considered to develop a $K_{S}$ dataset. In the scenario no. 2 (OPD), the OPD analysis (Eq.5) was applied to both $H_{1}$ and $H_{2}$ values and the resulting $K_{S}$ values were averaged (Elrick and Reynolds, 1992). This approach was suggested by Reynolds and Elrick (2002b) as an alternative calculation method to be applied when the TPD approach produces negative or unrealistic results. Finally, the scenario no. $3\left[\operatorname{OPD}\left(H_{1}\right)\right]$ included the $K_{S}$ data obtained by using Eq. (5) and the first ponded depth of water only $\left(H_{1}\right)$. This last scenario was considered since a singlelevel run is obviously more rapid and parsimonious in terms of applied water than a two-level run. According to Elrick and Reynolds (1992) and in accordance with previous investigations at the field site (Bagarello and Sgroi, 2007), $\alpha^{*}$ was set equal to 12 $\mathrm{m}^{-1}$ for all OPD calculations.

\section{Simplified falling head experiment}

An infiltration test of the SFH type was conducted in 12 randomly chosen locations within the experimental area. Applying this technique implies a relatively large insertion depth of the ring or the square box to be sure that a one-dimensional infiltration process is established during the run. However, a deep insertion increases the risk of compacting or shattering the sampled soil volume (Reynolds, 1993). To avoid this risk, a more conservative procedure (Bagarello et al., 2009b) was applied to confine cylindrical and cubic soil volumes having the same infiltration surface (Figure 1), although this choice, implying a rather demanding fieldwork for preparing the soil sample, implied that a relatively small number of points were sampled. In particular, six soil cylinders (height $=0.12$

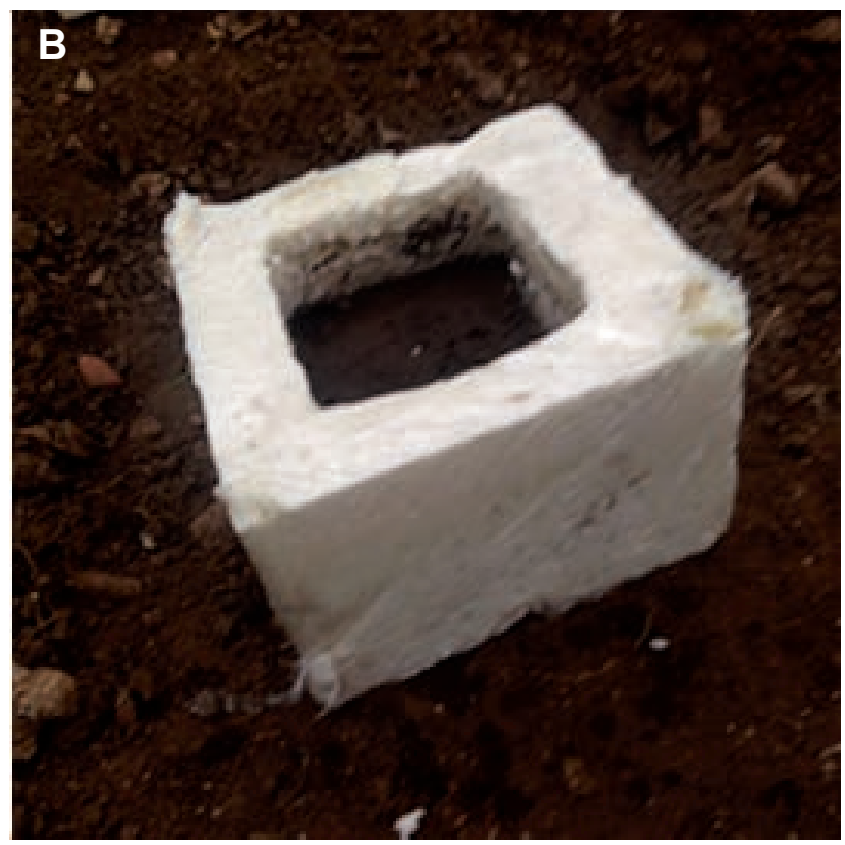

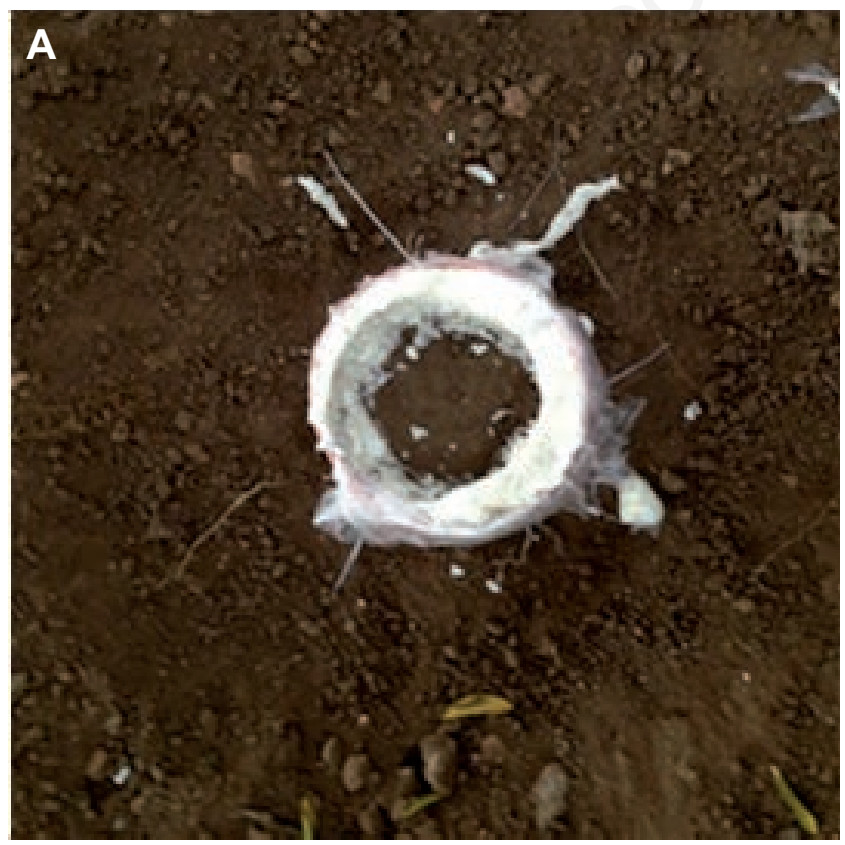

Figure 1. Examples of the cylindrical (A) and cubic (B) soil volumes sampled for the simplified falling head run. 
$\mathrm{m}$, diameter $=0.15 \mathrm{~m}$ ) and six soil cubes (height $=0.12 \mathrm{~m}$, side length $=0.135 \mathrm{~m}$ ) were manually exposed and covered along their walls by a casing in polyurethane foam (Bagarello and Sgroi, 2008). Initially, the soil was exposed by digging a small trench. A cylindrical or cubic packing case with open ends at both the top and the bottom were placed around the soil column and a stopper in polyurethane foam, previously prepared in the laboratory, was put on the surface of the column to prevent direct contact between the expanding foam and the upper end of the sampled soil volume. The $60-70 \%$ of the space between the packing case and the soil column was filled with polyurethane foam and a tablet and a small weight of 1-2 $\mathrm{kg}$ were placed on the upper end of the packing case to confine foam expansion only partially. After the foam hardened, the packing case was detached along two previously realised cutting lines, and the stopper was removed to expose the soil surface for the SFH run.

Undisturbed soil cores collected two days before the infiltration run were used to determine $\theta_{i}$ and $\rho_{b}$ and to obtain an estimate of $\theta_{s}$. Eq. (8) with $\alpha^{*}=12 \mathrm{~m}^{-1}$ was used to calculate $K_{s}$.

\section{Data summary}

To summarise the $K_{S}(\mathrm{PI}, \mathrm{SFH})$ and $\alpha^{*}(\mathrm{PI})$ data, the geometric mean and the associated coefficient of variation $(\mathrm{CV})$ were calculated using the appropriate lognormal equations (Lee et al., 1985) since these variables are commonly considered to be log normally distributed (Mohanty et al., 1994; Warrick, 1998). Arithmetic means and associated $C V \mathrm{~s}$ were calculated for $\rho_{b}$ and $\theta_{i}$.

\section{Results and discussion}

\section{Pressure infiltrometer experiment}

Regardless of the considered scenario, very similar $K_{s}$ (i.e., differing by a factor of 1.05-1.16, depending on the scenario) and $\alpha^{*}$ (factor of difference $=1.32$ ) values were obtained with the two sources when $r_{e q}$ for the square source was defined by Eq. (6), and the differences between two $K_{S}$ or $\alpha^{*}$ datasets (one for the circular source and the other for the square source) were never statistically significant according to a two tailed test at $\mathrm{P}=0.05$ (Table 3 ). Using Eq. (7) to define $r_{e q}$ did not produce significant differences between the two sets of $\alpha^{*}$ values but the differences were statistically significant, although not substantial (i.e., by a factor not exceeding 2.50), with reference to all $K_{S}$ calculation scenarios
(Table 3). Therefore, this investigation gave experimental support to the use of Eq. (6) for analysing PI data collected with a square source.

Consequently, a unique dataset was developed for the field site by pooling the data estimated with the ring and the square [Eq. (6) for $r_{e q}$ ] infiltrometer together.

Neither $\alpha^{*}$ nor $K_{S}$ were significantly correlated with $\rho_{b}$ and $\theta_{i}$, regardless of the considered scenario (Table 4). The lack of any $K_{S}$ and $\alpha^{*} v_{s} \rho_{b}$ and $\theta_{i}$ relationship was probably due to the fact that these last two parameters did not vary very much during the experimental period. In particular, $\rho_{b}$ values ranging from 0.95 to $1.28 \mathrm{~g}$ $\mathrm{cm}^{-3}$ (mean=1.12 $\mathrm{g} \mathrm{cm}^{-3}$ ) were obtained on the 20 sampling dates

Table 3. Summary statistics of the saturated soil hydraulic conductivity, $K_{s}$, and $\alpha^{*}$ parameter values obtained by the pressure infiltrometer with the circular and square sources.

\begin{tabular}{|c|c|c|c|c|c|}
\hline \multirow{2}{*}{ Source } & \multirow{2}{*}{ Statistics } & \multicolumn{4}{|c|}{ Scenario } \\
\hline & & $\frac{\mathrm{K}_{\mathrm{s}}}{\left(\mathrm{mm} \mathrm{h}^{-1}\right)}$ & $\begin{array}{c}\alpha^{*} \\
\left(m^{-1}\right)\end{array}$ & $\begin{array}{c}2 \\
\mathrm{~K}_{\mathrm{s}} \\
\left(\mathrm{mm} \mathrm{h}^{-1}\right)\end{array}$ & $\begin{array}{c}3 \\
\mathrm{~K}_{\mathrm{s}} \\
\left(\mathrm{mm} \mathrm{h}^{-1}\right)\end{array}$ \\
\hline Ring & $\begin{array}{l}\mathrm{N} \\
\text { Min } \\
\text { Max } \\
\text { Mean } \\
\text { CV (\%) }\end{array}$ & $\begin{array}{c}10 \\
24.2 \\
207.9 \\
106.3^{\mathrm{a}(\mathrm{b})} \\
67.7\end{array}$ & $\begin{array}{c}17 \\
1.02 \\
7.68 \\
2.84^{\mathrm{ab}} \\
73.6\end{array}$ & $\begin{array}{c}19 \\
52.0 \\
378.9 \\
220.0^{\mathrm{a}(\mathrm{b})} \\
50.9\end{array}$ & $\begin{array}{c}19 \\
56.7 \\
404.5 \\
233.4^{\text {a(b) }} \\
52.0\end{array}$ \\
\hline $\begin{array}{l}\text { Square } \\
\left(\mathrm{r}_{\mathrm{eq}}=\mathrm{l} / \pi^{0.5}\right)\end{array}$ & $\begin{array}{l}\text { N } \\
\text { Min } \\
\text { Max } \\
\text { Mean } \\
\text { CV (\%) }\end{array}$ & $\begin{array}{c}17 \\
52.5 \\
202.5 \\
123.7^{\mathrm{a}} \\
40.3\end{array}$ & $\begin{array}{c}17 \\
1.11 \\
17.6 \\
3.71^{\mathrm{a}} \\
70.6\end{array}$ & $\begin{array}{c}20 \\
106.5 \\
387.2 \\
233.7^{\mathrm{a}} \\
31.1\end{array}$ & $\begin{array}{c}20 \\
105.1 \\
426.3 \\
245.3^{\mathrm{a}} \\
33.1\end{array}$ \\
\hline $\begin{array}{l}\text { Square } \\
\left(\mathrm{r}_{\mathrm{eq}}=\mathrm{l}\right)\end{array}$ & $\begin{array}{l}\mathrm{N} \\
\text { Min } \\
\text { Max } \\
\text { Mean } \\
\text { CV (\%) }\end{array}$ & $\begin{array}{c}17 \\
22.7 \\
91.4 \\
54.0^{(\mathrm{b})} \\
41.4\end{array}$ & $\begin{array}{c}17 \\
1.15 \\
43.1 \\
4.45^{\mathrm{b}} \\
95.3\end{array}$ & $\begin{array}{c}20 \\
40.8 \\
148.0 \\
90.1^{(b)} \\
31.6\end{array}$ & $\begin{array}{c}20 \\
39.7 \\
161.0 \\
93.5^{(\mathrm{b})} \\
33.4\end{array}$ \\
\hline
\end{tabular}

In the scenario no. 1 (two-ponding depth approach), $K_{s}$ and $\alpha^{*}$ were calculated by Eqs. (3) and (4) and the two-level runs yielding positive results for the two variables and $\alpha^{*}$ values of $1-100 \mathrm{~m}^{-1}$ were included in the dataset. In the scenario no. 2 (one-ponding depth approach, OPD), $\alpha^{*}$ was estimated on the basis of textural/structural considerations and $K_{s}$ was calculated by Eq. (5); the OPD analysis was applied to both $H_{l}$ and $H_{2}$ and the two resulting $K_{s}$ values were averaged. The scenario no. 3 [OPD $\left.\left(H_{l}\right)\right]$ was similar to the scenario no. 2, but only the $K_{S}$ data corresponding to the first ponded depth of water $\left(H_{l}\right)$ were considered. For a given column, mean values followed by the same lower case letter not enclosed in parenthesis are not significantly different according to a two-tailed t test at $\mathrm{P}=0.05$. ${ }^{\mathrm{a}, \mathrm{b}, \mathrm{b})}$ Mean values followed by the same letter enclosed in parenthesis are significantly different. CV, coefficient of variation.

Table 4. Results of the linear regression analysis of saturated soil hydraulic conductivity, $K_{s}\left(\mathrm{~mm} \mathrm{~h}^{-1}\right)$, and $\alpha^{*}$ parameter $\left(\mathrm{m}^{-1}\right)$ against dry soil bulk density, $\rho_{b}\left(\mathrm{~g} \mathrm{~cm}^{-3}\right)$, and initial soil water content, $\theta_{\mathrm{i}}\left(\mathrm{m}^{3} \mathrm{~m}^{-3}\right)$.

\begin{tabular}{|c|c|c|c|}
\hline Scenario & Dependent variable & Independent variable & Coefficient of determination, $\mathrm{R}^{2}$ \\
\hline \multirow[t]{4}{*}{1} & $K_{S}$ & $\rho_{b}$ & $0.053 \mathrm{~ns}$ \\
\hline & $K_{S}$ & $\theta_{\mathrm{i}}$ & $0.022 \mathrm{~ns}$ \\
\hline & $\alpha^{*}$ & $\rho_{b}$ & $0.143 \mathrm{~ns}$ \\
\hline & $\alpha^{*}$ & $\theta_{\mathrm{i}}$ & $0.028 \mathrm{~ns}$ \\
\hline \multirow[t]{2}{*}{2} & $K_{S}$ & $\rho_{b}$ & $0.049 \mathrm{~ns}$ \\
\hline & $K_{S}$ & $\theta_{\mathrm{i}}$ & $0.032 \mathrm{~ns}$ \\
\hline \multirow[t]{2}{*}{3} & $K_{S}$ & $\rho_{b}$ & $0.035 \mathrm{~ns}$ \\
\hline & $K_{S}$ & $\theta_{\mathrm{i}}$ & $0.025 \mathrm{~ns}$ \\
\hline
\end{tabular}

In the scenario no. 1 (two-ponding depth approach), $K_{s}$ and $\alpha^{*}$ were calculated by Eqs. (3) and (4) and the two-level runs yielding positive results for the two variables and $\alpha^{*}$ values of 1-100 $\mathrm{m}^{-1}$ were included in the dataset. In the scenario no. 2 (one-ponding depth approach, OPD), $\alpha^{*}$ was estimated on the basis of textural/structural considerations and $K_{S}$ was calculated by Eq. (5); the OPD analysis was applied to both $H_{l}$ and $H_{2}$ and the two resulting $K_{S}$ values were averaged. The scenario no. $3\left[\mathrm{OPD}\left(H_{l}\right)\right]$ was similar to the scenario no. 2, but only the $K_{S}$ data corresponding to the first ponded depth of water (H1) were considered. ns, coefficient of correlation not significantly greater than zero according to a two-tailed t test at $\mathrm{P}=0.05$. 
but the $C V\left(\rho_{b}\right)$ was low, i.e., equal to $7.8 \%$. On the other hand, $\theta_{i}$ values varying between 0.07 and $0.24 \mathrm{~m}^{3} \mathrm{~m}^{-3}$ (mean=0.13 $\mathrm{m}^{3} \mathrm{~m}^{-3}$ ) were measured and the corresponding $C V$ was appreciably higher, i.e., equal to $45.1 \%$. However, most (i.e., $80 \%$ ) of the $\theta_{i}$ values were lower than $0.20 \mathrm{~m}^{3} \mathrm{~m}^{-3}$, since relatively dry soil conditions made the access to the field easier, and the $K_{S}$ values measured at the field site were found not to depend on $\theta_{i}$ for $\theta_{i}<0.20 \mathrm{~m}^{3} \mathrm{~m}^{-3}$ (Bagarello and Sgroi, 2007). This last finding was based on a $K_{s}$ measurement campaign made with the SFH technique but Bagarello and Sgroi (2007) also showed that similar $K_{S}$ values were obtained with the PI.

Considering the developed dataset for the scenario no. $1, \alpha^{*}$ was found to significantly increase with $K_{S}$ (Figure 2). This result gave additional support to previous investigations suggesting that soils with high values of the $\alpha^{*}$ parameter, which is indicative of a relatively low importance of capillarity on steady flow (Reynolds et al., 1992), should be expected to also have high $K_{S}$ values (White and Sully, 1992; Yitayew et al., 1998; Bagarello et al., 2014b).

Following Reynolds and Zebchuk (1996), the Tukey's honestly significant difference test was applied to compare the $K_{s}$ values obtained with the three considered scenarios (Table 5). Significantly lower results were obtained with the TPD approach (scenario no. 1) than the two OPD approaches (scenario no. 2 and 3 ) that yielded statistically equivalent $K_{S}$ values. In any case, differences were not substantial since the means differed at the most by 2.05 times and an error of the estimate of $K_{S}$ by a factor of two or three can be considered acceptable for many practical purposes (Elrick and Reynolds, 1992; Reynolds and Zebchuk, 1996; Elrick et al., 2002). The coefficients of variation also were similar among the three tested approaches since they varied within the rather narrow range of $41-51 \%$. The $\alpha^{*}$ parameter was lower than expected on the basis of the textural and structural characteristics of the sampled soil (Elrick and Reynolds, 1992). However, it was very close to the mean $\alpha^{*}$ parameter $\left(3.3 \mathrm{~m}^{-1}\right)$ obtained in former investigations conducted at the same field site with the PI and the TPD approach by Bagarello et al. (2009b, 2013b). Therefore, the two tested OPD approaches were practically equivalent but lower $K_{s}$ values, and unexpectedly low $\alpha^{*}$ values, were obtained with the TPD approach.

Attempting to explain these results, a comparison was initially established between the $K_{S}$ values obtained with the $\operatorname{OPD}\left(H_{1}\right)$ approach (scenario no. 3) and the corresponding values obtained by applying a similar approach [i.e., Eq. (5) and $\alpha^{*}=12 \mathrm{~m}^{-1}$ ] with the estimated steady state flow rates for $H=H_{2}\left(Q_{s 2}\right)$. This comparison was made with reference to 37 data points since only $Q_{s 1}$ was measured in two infiltration runs. With a very few exceptions (two out of the 37 cases), lower $K_{s}$ values were obtained with $H_{2}$ than $H_{1}$, with a mean ratio between these two estimates of 0.89 (Figure 3 ). According to this result, the differences between the two $K_{S}$ values were small and probably negligible form a practical point of view. However, the established comparison also suggested occurrence of underestimation of $Q_{s 2}$ or overestimation of $Q_{s 1}$, or both, during the field infiltration runs.

To test what happens with the TPD approach in these cases, the three representative sand $\left(K_{s}=1 \times 10^{-4} \mathrm{~m} \mathrm{~s}^{-1}, \alpha^{*}=36 \mathrm{~m}^{-1}\right)$, loam $\left(K_{S}=1 \times 10^{-6} \mathrm{~m} \mathrm{~s}^{-1}, \alpha^{*}=12 \mathrm{~m}^{-1}\right)$ and clay $\left(K_{s}=1 \times 10^{-8} \mathrm{~m} \mathrm{~s}^{-1}, \alpha^{*}=4\right.$ $\mathrm{m}^{-1}$ ) soils according to Reynolds and Elrick (1990) were considered and the true $Q_{s 1}$ and $Q_{s 2}$ values were calculated by Eqs. (1) and (2). In other terms, the calculated steady-state flow rates for $H_{1}=0.053 \mathrm{~m}$ and $H_{2}=0.11 \mathrm{~m}$, respectively, were those expected for the three theoretical soils according to the model by Reynolds and Elrick (1990). Then, $K_{S}$ and $\alpha^{*}$ were calculated by Eqs. (2), (3) and
(4), i.e., the TPD approach, considering a 5\% and a $10 \%$ error in the estimation of $Q_{s 1}$ (true value + error) and/or $Q_{s 2}$ (true value error). Only an overestimation was considered for the lower ponded level $\left(H_{1}\right)$ since field runs have unavoidably a limited duration

Table 5. Summary statistics of the saturated soil hydraulic conductivity, $K_{s}\left(\mathrm{~mm} \mathrm{~h}^{-1}\right)$, and $\alpha^{*}$ parameter $\left(\mathrm{m}^{-1}\right)$ values obtained by pooling the data collected with the ring and the square pressure infiltrometer together.

\begin{tabular}{lcccc} 
Statistic & \multicolumn{3}{c}{ Scenario } & \\
& $K_{S}$ & $a^{*}$ & $K_{S}$ & $K_{S}$ \\
$\mathrm{~N}$ & 27 & 27 & 39 & 39 \\
Min & 24.2 & 1.02 & 52.0 & 56.7 \\
\hline Max & 207.9 & 17.6 & 387.2 & 426.3 \\
Mean & $116.9^{\mathrm{a}}$ & 3.36 & $226.9^{\mathrm{b}}$ & $239.4^{\mathrm{b}}$ \\
\hline CV (\%) & 50.7 & 71.8 & 41.1 & 42.5 \\
\hline
\end{tabular}

In the scenario no. 1 (two-ponding depth approach), $K_{S}$ and $\alpha^{*}$ were calculated by Eqs. (3) and (4) and the two-level runs yielding positive results for the two variables and $\alpha^{*}$ values of $1-100 \mathrm{~m}^{-1}$ were included in the dataset. In the scenario no. 2 (one-ponding depth approach, OPD), $\alpha^{*}$ was estimated on the basis of textural/structural considerations and $K_{s}$ was calculated by Eq. (5); the OPD analysis was applied to both $H_{l}$ and $H_{2}$ and the two resulting $K_{s}$ values were averaged. The scenario no. 3 [OPD $\left.\left(H_{l}\right)\right]$ was similar to the scenario no. 2, but only the $K_{S}$ data corresponding to the first ponded depth of water $\left(H_{l}\right)$ were considered. a,bMean values of $K_{s}$ followed by a different letter are significantly different according to the Tukey's honestly significant difference test at $\mathrm{P}=0.05$. CV, coefficient of variation.

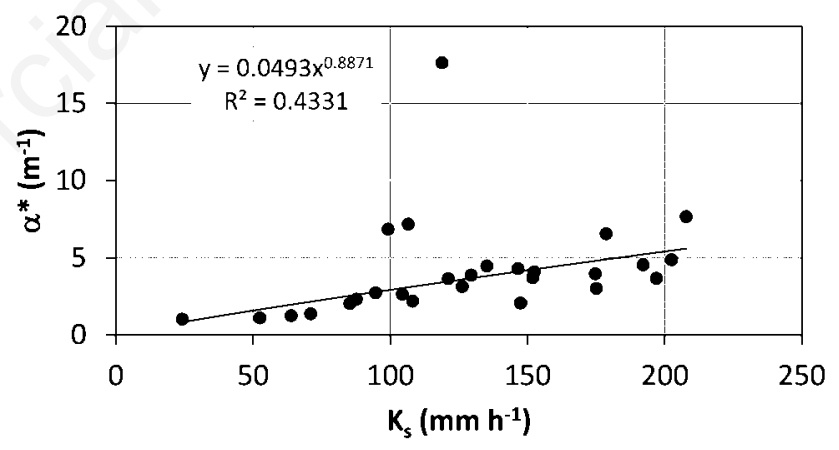

Figure 2. Relationship between the $\alpha^{*}$ parameter and the saturated soil hydraulic conductivity, $K_{s}$.

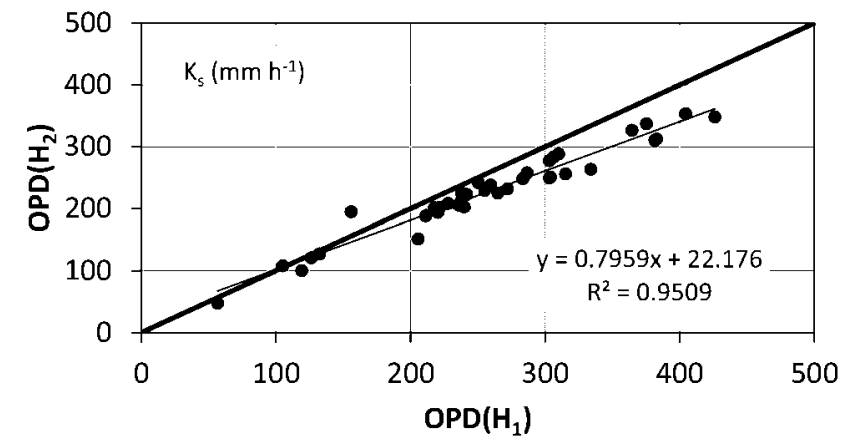

Figure 3. Comparison between the saturated soil hydraulic conductivity, $K_{s}$, values determined by applying the one-ponding depth (OPD) approach with the estimated steady state flow rates for the first $\left(H_{1}\right)$ and the second $\left(H_{2}\right)$ ponded head of water during the infiltration run. 
for practical reasons and the decrease of flow rates to steady-state conditions can be long, especially in fine textured and initially dry soils (Reynolds, 1993; Reynolds and Elrick, 2002b). Prolonged wetting is expected to weaken the soil aggregates because it lowers their cohesiveness, soften the cements and causes clay particle swelling (Morgan, 2005). All these phenomena are expected to induce a decrease in flow rates into the soil and, for this reason, only an underestimation was considered for the higher ponded level $\left(H_{2}\right)$. With a single exception (clay soil, $10 \%$ overestimation of $Q_{s 1}$ and $10 \%$ underestimation of $Q_{s 2}$ ), simultaneously positive $K_{S}$ and $\alpha^{*}$ values were obtained and $\alpha^{*}$ varied between 1.03 and $21.7 \mathrm{~m}^{-1}$, which means that there were signs of a successful twolevel run. However, both $K_{S}$ and $\alpha^{*}$ were systematically underestimated (Figure 4). A single error (overestimation of $Q_{s 1}$ or underestimation of $Q_{s 2}$ ) was enough to determine erroneous $K_{s}$ and $\alpha^{*}$ predictions and the absolute value of the prediction error was highest when overestimation of $Q_{s 1}$ and underestimation of $Q_{s 2}$ occurred simultaneously. Larger errors in $Q_{s}$ implied larger differences between the estimated and the true soil hydraulic parameters. Considering the scenario no. 2 (OPD) with the true $\alpha^{*}$ parameter and the same error levels for $Q_{s 1}$ and $Q_{s 2}$, the error of the estimated $K_{S}$ varied from $-5 \%$ to $+5 \%$. With reference to the scenario no. 3 [OPD $\left(H_{1}\right)$, only the error in $Q_{s 1}$ was considered], the error of the $K_{S}$ prediction did not exceed $10 \%$. These last results were expected taking into account that $K_{S}$ is directly proportional to $Q_{s}$ according to Eq. (5).

Therefore, this analysis showed that, with the TPD approach, excessively low $K_{S}$ and $\alpha^{*}$ values have to be expected as a consequence of a small overestimation of $Q_{s 1}$, a small underestimation of $Q_{s 2}$ or both. Taking into account that, in practice, the errors in the calculated soil hydraulic parameters could not be detectable, since physically possible and also plausible results are obtained by the two-level analysis, the conclusion should be that the OPD approach has to be preferred in general to the TPD approach. This suggestion is based on the circumstance that single-level calculations appear to be less sensitive to small uncertainties in the estimated steady-state flow rates than two-level calculations, but also on the premise that no uncertainties affect the estimate of $\alpha^{*}$, which cannot be always true. Fortunately, a reduced variability of $\alpha^{*}$ has to be expected (Reynolds and Elrick, 2002a).

Underestimation of $K_{S}$ and $\alpha^{*}$ by the TPD approach is likely a consequence of overestimation of $Q_{s 1}$ and underestimation of $Q_{s 2}$. Steady-state conditions are slowly approached for the first infiltration run, particularly in medium- to fine-textured soils, which can imply an erroneous estimate of steady-state flow rate (e.g., Bagarello et al., 1999; Reynolds et al., 2000; Reynolds and Elrick, 2002b). However, with reference to this experimental investigation, overestimation of $Q_{s 1}$ was considered a less likely cause of the low $K_{s}$ and $\alpha^{*}$ values by the TPD approach since convincing near steady-state conditions were detected for $H=H_{1}$ in all cases (Figure 5). Conversely, the low $K_{S}$ and $\alpha^{*}$ values by the TPD approach were more likely attributable to a systematic underestimation of $Q_{s 2}$. The theoretical model by Reynolds and Elrick (1990), i.e., Eq. (1), was developed under the hypothesis of an initially uniformly unsaturated soil. When the first ponding depth of water $\left(H_{1}\right)$ is established on the infiltration surface, the hypothesis of a uniform $\theta_{i}$ can perhaps be considered plausible. However, when the subsequent ponding depth of water $\left(H_{2}>H_{1}\right)$ is established on the infiltration surface, it is certain that the soil is initially wet (saturated, $\theta_{S}$ ) below the infiltration surface, and relatively dry (antecedent soil water content, $\theta_{i}$ ) outside the wetting front formed at the end of the run with the $H_{1}$ level. Therefore, the uniform $\theta_{i}$ hypothesis of the wetted soil at the beginning of the run with the $\mathrm{H}_{2}$ level is no longer valid. The TPD approach assumes that $\phi_{m}$ does not vary in the passage from $H_{1}$ to $H_{2}$ but a higher initial soil water content implies smaller values of $\phi_{m}$ in Eq. (1) and hence smaller steady-state flow rates. Therefore, the measured $Q_{s 2}$ value could be expected to be lower than the one that would theoretically allow use of Eqs. (3) for calculation of soil hydraulic parameters. However, a check of this reasoning appears necessary since, at steady-state, the wetted soil volume with $H=H_{2}$ envelopes that corresponding to $H=H_{1}$. Therefore, $\theta$ is equal to $\theta_{i}$ outside the wetting front for both $H=H_{1}$ and $H=H_{2}$, and the $\theta_{i}$ uniformity hypothesis could also be valid for the analysis of steady-state flow rates. Other reasons for lower than expected $Q_{s 2}$ values are of practical nature. As time passes, swelling phenomena, reducing macropore volume, have more opportunity to occur, also in soils with a low clay content (Bagarello and Sgroi, 2007), and obstruction of macropores become more likely since particle bonds are weakened by prolonged wetting. Moreover, some turbulence at the infiltration surface can occur in the passage from $H_{1}$ to $H_{2}$. Finally, low $Q_{s 2}$ values could also be due to a low permeability layer close to the bottom edge of the ring.

In conclusion, the estimate of $Q_{s}$ appeared more reliable than that of $Q_{s 2}$ and therefore the $K_{s}$ values obtained with the scenario no. 3 were used for the subsequent comparison with the SFH technique. In other terms, the OPD approach appears to be less sensitive to $Q_{s}$ approximations than the TPD approach and, in particular,
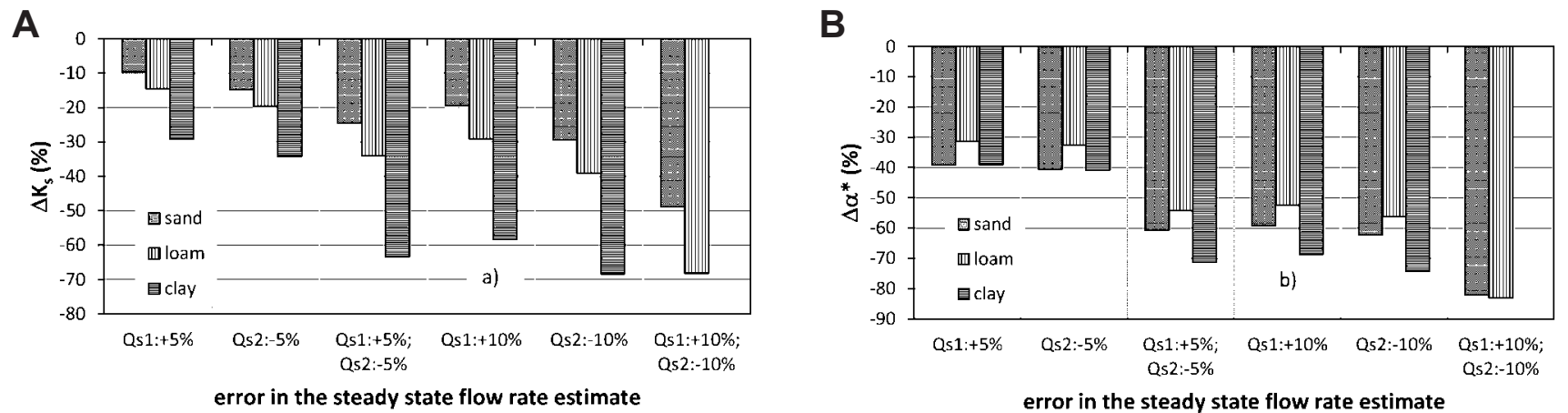

Figure 4. Errors $\left[\Delta=\left(\right.\right.$ estimated - true)/true] in the A) $K_{s}$ and B) $\alpha^{*}$ values calculated by the two-ponding depth approach with erroneous estimates of $Q_{s 1}, Q_{s 2}$ or both for the three representative soils by Reynolds and Elrick (1990). 
A

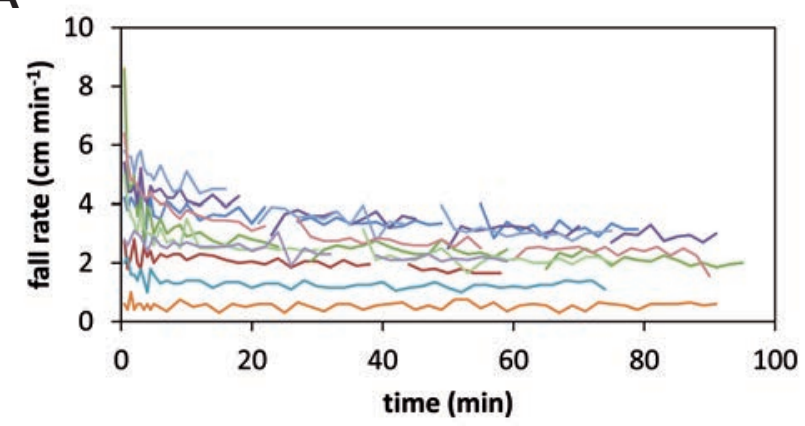

C

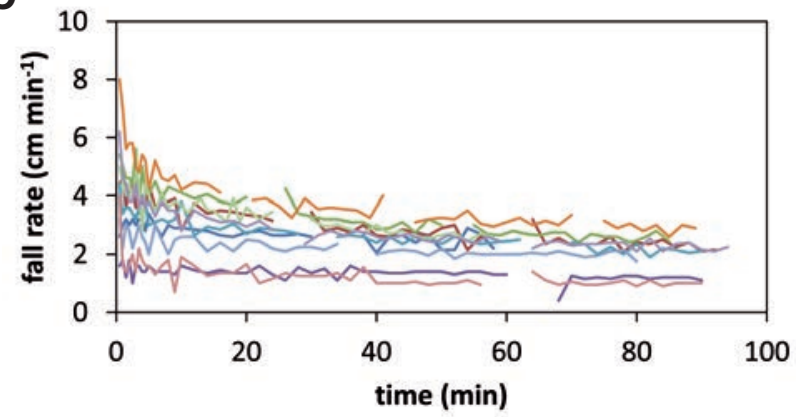

B

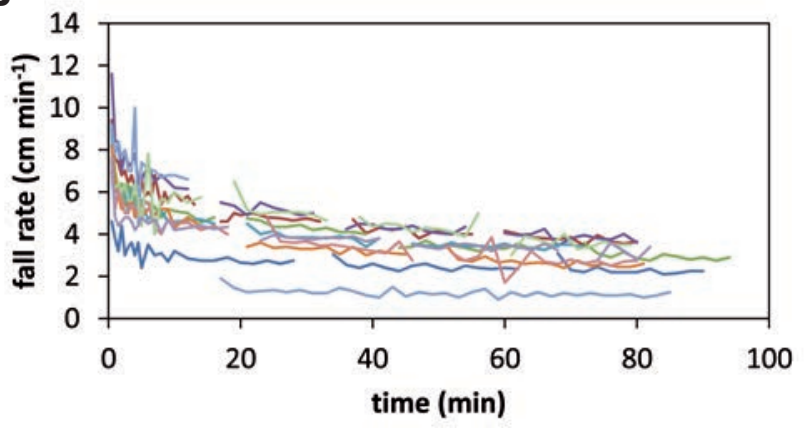

D

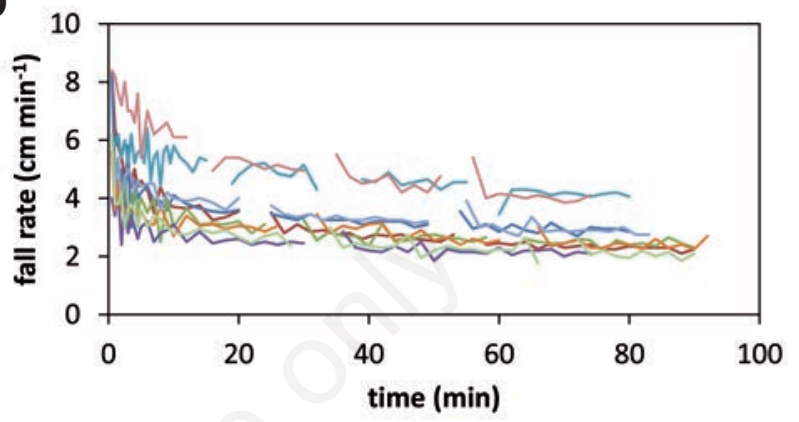

Figure 5. A-D) Experimental relationships between the rate of fall of the water level in the pressure infiltrometer reservoir and the time from the beginning of the process for the field runs carried out with the first ponded depth of water $\left(H_{1}=53 \mathrm{~mm}\right)$.

using $Q_{s 1}$ is better than considering both $Q_{s 1}$ and $Q_{s 2}$ (scenario no. 2) since only one source of errors is included in the former approach.

\section{Simplified falling head experiment}

Very similar $K_{S}$ values (i.e., differing by a factor of 1.19) were obtained with the two sources (circular, square) by the transient SFH experiment and the differences between the two $K_{S}$ datasets were not statistically significant according to a two-tailed t test at $\mathrm{P}=0.05$ (Table 6). Therefore, this investigation gave experimental support to the theoretically expected equivalence of the two sources since a one-dimensional infiltration process is established with the SFH technique.

A unique dataset was developed with all the SFH data (Table 6) and a comparison with the PI results (Table 5, scenario no. 3 ) was established by a two-tailed t test performed on $\ln \left(K_{S}\right)$. The difference between the mean values of $K_{S}\left(139.7 \mathrm{~mm} \mathrm{~h}^{-1}\right.$ for the SFH technique and $239.4 \mathrm{~mm} \mathrm{~h}^{-1}$ for the PI) was statistically significant $(\mathrm{P}=0.05)$ but not substantial (means differing by 1.71 times). Moreover, all $K_{S}$ values obtained with the SFH technique fell within the range of the $K_{S}$ values obtained with the PI. Therefore, it seems plausible to suggest that detecting a statistical significance of the difference between the means was a consequence of the reduced number of data collected with the SFH technique. In other words, larger sample sizes for the transient technique should be expected to increase the probability to detect clearer similarities with the steady-state technique, i.e., even from a statistical point of view.

\section{Comparison with previous experiments}

The mean $K_{S}$ values obtained in this investigation with the PI and SFH runs were in line with the saturated conductivity previously measured at the same field site with the same techniques and

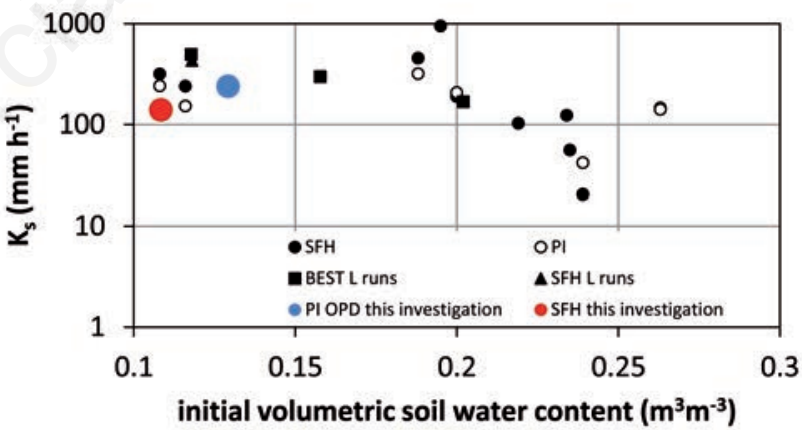

Figure 6. Effect of the initial volumetric soil water content on the mean saturated soil hydraulic conductivity, $K_{s}$, obtained at the field site in this and other investigations (Bagarello and Sgroi, 2007; Bagarello et al., 2014b; Alagna et al., 2016a) with different experimental methodologies. SFH, simplified falling head; OPD, one-ponding depth; PI, pressure infiltrometer.

Table 6. Summary statistics of the field saturated soil hydraulic conductivity, $K_{s}\left(\mathrm{~mm} \mathrm{~h}^{-1}\right)$, values obtained by the simplified falling head technique with the circular and square sources.

\begin{tabular}{lccc} 
Statistic & Ring & Square & All data \\
N & 6 & 6 & 12 \\
Min & 120.0 & 126.3 & \\
\hline Max & 135.3 & 218.9 & \\
Mean & $128.3^{\mathrm{a}}$ & $152.2^{\mathrm{a}}$ & 139.7 \\
\hline CV $(\%)$ & 4.3 & 19.1 & 15.9 \\
\hline
\end{tabular}

aMean values followed by the same letter are not significantly different according to a two-tailed $t$ test at $\mathrm{P}=0.05$. $\mathrm{CV}$, coefficient of variation. 
also with other techniques, such as the so called BEST procedure of soil hydraulic characterisation by Lassabatere et al. (2006) (Figure 6) (Bagarello and Sgroi, 2007; Bagarello et al., 2014b; Alagna et al., 2016a). In particular, it was confirmed that high $K_{s}$ values have to be expected at the field site when the soil is initially relatively dry.

\section{Conclusions}

According to this investigation, the classical steady-state analysis of PI data is usable if a square infiltrometer is employed in the field. In this case, however, an equivalent radius has to be used in the calculations. In particular, it is possible to assume that infiltration occurs through a circular surface having the same area of the square infiltrometer. Assuming that the ring radius coincides with the side length of the infiltrometer is not recommended.

A plausible $\alpha^{*}$ value, i.e., falling within the realistic range of 1 to $100 \mathrm{~m}^{-1}$, together with positive estimates of both $K_{s}$ and $\alpha^{*}$, is not always indicative of reliable TPD calculations. In addition, excessively low $K_{S}$ and $\alpha^{*}$ values have to be expected with the TPD approach as a consequence of a small overestimation of $Q_{s 1}$, a small underestimation of $Q_{s 2}$ or both. Overestimating $Q_{s 1}$ and underestimating $Q_{s 2}$ is a practical possibility during application of the PI in the field for different reasons of experimental nature, such as a too short duration of the first phase of the run $\left(H=H_{1}\right)$ or the weakening of particle bonds by prolonged wetting (during the $H=H_{2}$ phase). Reasons of theoretical nature could also be suggested, taking into account that the soil is wetter at the beginning of the second phase of the two-level run than the first one. This circumstance could imply that the measured $Q_{s 2}$ value is lower than the one that would theoretically allow use of the analytical model for calculation of soil hydraulic parameters. However, this reasoning is not free from doubts since, at steady state, a higher $H$ value determines wetting of larger soil volumes.

This is one of the reasons why the OPD approach with steadystate flow rate estimated under homogeneous initial moisture conditions (i.e., $Q_{s 1}$ ) appears to be the most appropriate way to analyse the PI data. An additional reason is that estimating $\alpha^{*}$ on the basis of the soil texture and structure characteristics appears a relatively straightforward task since a very limited number of soil categories have been defined. Clearly, the conclusion that the simplest PI run yields the most reliable $K_{S}$ data needs additional support.

Finally, despite limited to a single soil, this investigation confirmed that, as predicted by theory, the SFH technique can be applied with both circular and square sources since the shape of the infiltration surface does not influence the measured $K_{S}$ values.

Theoretical developments on source shape effects for ponding infiltration experiments are advisable since the currently used equations for $K_{S}$ estimation were derived for a circular infiltration source, which implies radial symmetry of the flux under and outside the ring. Radial symmetry cannot be assumed if the infiltration source has a square shape and the use of an equivalent radius represents a practical means to estimate $K_{S}$ from infiltration data collected by square sources. A topic to be developed experimentally is the comparison between the PI and SFH techniques. In particular, establishing in detail what are the sample size effects on the results of a comparison between these two techniques appear advisable. Even if some error is surely included in the $K_{s}$ estimation by using the equations developed for the circular source, in this application such error turned out to be negligible compared to the spatial and temporal variability (i.e., the mean values were not significantly different) and, thus, square infiltration appears to be a practical way to characterise the soil.

\section{References}

Agnese C., Bagarello V., Baiamonte G., Iovino M. 2011. Comparing physical quality of forest and pasture soils in a Sicilian watershed. Soil Sci. Soc. Am. J. 75:1958-70.

Alagna V., Bagarello V., Di Prima S., Giordano G., Iovino M. 2016a. Testing infiltration run effects on the estimated water transmission properties of a sandy-loam soil. Geoderma 267:24-33.

Alagna V., Bagarello V., Di Prima S., Iovino M. 2016 b. Determining hydraulic properties of a loam soil by alternative infiltrometer techniques. Hydrol. Process. 30:263-75.

Angulo-Jaramillo R., Bagarello V., Iovino M., Lassabatere L. 2016. Infiltration Measurements for soil hydraulic characterisation. Springer, Berlin, Germany.

Angulo-Jaramillo R., Vandervaere J.-P., Roulier S., Thony J.L., Gaudet J.P., Vauclin M. 2000. Field measurement of soil surface hydraulic properties by disc and ring infiltrometers. A review and recent developments. Soil Till. Res. 55:1-29.

Bagarello V., Baiamonte G., Castellini M., Di Prima S., Iovino M. 2014a. A comparison between the single ring pressure infiltrometer and simplified falling head techniques. Hydrol. Process. 28:4843-53.

Bagarello V., Castellini M., Di Prima S., Iovino M. 2014b. Soil hydraulic properties determined by infiltration experiments and different heights of water pouring. Geoderma 213:492-501.

Bagarello V., Di Stefano C., Ferro V., Iovino M., Sgroi A. 2010. Physical and hydraulic characterisation of a clay soil at the plot scale. J. Hydrol. 387:54-64.

Bagarello V., Di Stefano C., Iovino M., Sgroi A. 2013a. Using a transient infiltrometric technique for intensively sampling field-saturated hydraulic conductivity of a clay soil in two runoff plots. Hydrol. Process. 27:3415-23.

Bagarello V., Giordano G., Iovino M., Sgroi A. 2009b. Effetto della dimensione dell'anello sulla conducibilità idraulica del suolo saturo misurata con la tecnica SFH. Atti del IX Convegno Nazionale dell'Associazione Italiana di Ingegneria Agraria, Ischia Porto, 12-16 Settembre, memoria n. 3-4 [In Italian].

Bagarello V., Iovino M. 1999. Spatial and temporal variability of saturated hydraulic conductivity in a central Sicily soil. pp 249-256 in Proc. International Workshop of EurAgEng's Field of Interest on Soil and Water "Modelling of Transport Processes in Soils", Leuven, Belgium.

Bagarello V., Iovino M., Elrick D. 2004. A simplified falling-head technique for rapid determination of field-saturated hydraulic conductivity. Soil Sci. Soc. Am. J. 68:66-73.

Bagarello V., Iovino M., Lai J. 2013b. Field and numerical tests of the two-ponding depth procedure for analysis of single-ring pressure infiltrometer data. Pedosphere 23:779-89.

Bagarello V., Iovino M., Lai J. 2016. Testing steady-state analysis of single-ring and square pressure infiltrometer data. Geoderma 261:101-9.

Bagarello V., Iovino M., Reynolds W.D. 1999. Measuring hydraulic conductivity in a cracking clay soil using the Guelph parameter. Trans. ASAE 42:957-64.

Bagarello V., Iovino M., Tusa G. 2000. Factors affecting measurement of the near saturated soil hydraulic conductivity. Soil Sci. 
Soc. Am. J. 64:1203-10.

Bagarello V., Sferlazza S., Sgroi A. 2009a. Comparing two methods of analysis of single-ring infiltrometer data for a sandyloam soil. Geoderma 149:415-20.

Bagarello V., Sgroi A. 2004. Using the single-ring infiltrometer method to detect temporal changes in surface soil field-saturated hydraulic conductivity. Soil Till. Res. 76:13-24.

Bagarello V., Sgroi A. 2007. Using the simplified falling head technique to detect temporal changes in field-saturated hydraulic conductivity at the surface of a sandy loam soil. Soil Till. Res. 94:283-94.

Bagarello V., Sgroi A. 2008. Testing soil encasing materials for measuring hydraulic conductivity of a sandy-loam soil by the cube methods. Soil Sci. Soc. Am. J. 72:1048-57.

Bouma J. 1982. Measuring the hydraulic conductivity of soil horizons with continuous macropores. Soil Sci. Soc. Am. J. 46:438-41.

Ciollaro G., Lamaddalena N. 1998. Effect of tillage on the hydraulic properties of a vertic soil. J. Agr. Eng. Res. 71:147-55.

Elrick D.E., Angulo-Jaramillo R., Fallow D.J., Reynolds W.D., Parkin, G.W. 2002. Analysis of infiltration under constant head and falling head conditions. In: P.A.C. Raats, D. Smiles and A.W. Warrick (Eds.), Environmental mechanics: water, mass and energy trans-fer in the biosphere; Geophysical Monograph Series, 129. American Geophysical Union, Washington, DC, USA, pp 47-53.

Elrick D.E., Reynolds W.D. 1992. Methods for analysing constanthead well permeametre data. Soil Sci. Soc. Am. J. 56:320-3.

Gómez J.A., Vanderlinden K., Nearing M.A. 2005. Spatial variability of surface roughness and hydraulic conductivity after disk tillage: implications for runoff variability. J. Hydrol. 311:143-56.

Lassabatere L., Angulo-Jaramillo R., Soria Ugalde J.M., Cuenca R., Braud I., Haverkamp R. 2006. Beerkan estimation of soil transfer parameters through infiltration experiments - BEST. Soil Sci. Soc. Am. J. 70:521-32.

Lee D.M., Reynolds W.D., Elrick D.E., Clothier B.E. 1985. A comparison of three field methods for measuring saturated hydraulic conductivity. Can. J. Soil Sci. 65:563-73.

Mertens J., Jacques D., Vanderborght J., Feyen J. 2002. Characterisation of the field-saturated hydraulic conductivity on a hillslope: in situ single ring pressure infiltrometer measurements. J. Hydrol. 263:217-29.

Mohanty B.P., Ankeny M.D., Horton R., Kanwar R.S. 1994. Spatial analysis of hydraulic conductivity measured using disc infiltrometers. Water Resour. Res. 30:2489-98.

Morgan R.P.C. 2005. Soil erosion and conservation. Blackwell Publishing, London, UK.

Philip J.R. 1992. Falling head ponded infiltration. Water Resour. Res. 28:2147-8.

Reynolds W.D. 1993. Chapter 56. Saturated hydraulic conductivity: field measurement. In: M.R. Carter (Ed.), Soil sampling and methods of analysis, Canadian Society of Soil Science. Lewis Publishers, Boca Raton, FL, USA, pp 599-613.
Reynolds W.D., Bowman B.T., Brunke R.R., Drury C.F., Tan C.S. 2000. Comparison of tension infiltrometer, pressure infiltrometer, and soil core estimates of saturated hydraulic conductivity. Soil Sci. Soc. Am. J. 64:478-84.

Reynolds W.D., Elrick D.E. 1990. Ponded infiltration from a single ring: I. Analysis of steady flow. Soil Sci. Soc. Am. J. 54:1233-41.

Reynolds W.D., Elrick D.E. 2002a. 3.4.1.1 Principles and parameter definitions. In: J.H. Dane and G.C. Topp (co-eds.), Methods of soil analysis; Part 4, Physical methods; No. 5 in the Soil Science Society of America Book Series. Soil Science Society of America, Inc., Madison, WI, USA, pp 797-801.

Reynolds W.D., Elrick D.E. 2002b. 3.4.3.2.b Pressure infiltrometer. In: J.H. Dane and G.C. Topp (co-eds.), Methods of soil analysis; Part 4, Physical methods; No. 5 in the Soil Science Society of America Book Series. Soil Science Society of America, Inc., Madison, WI, USA, pp 826-836.

Reynolds W.D., Elrick D.E., Youngs E.G., 2002. 3.4.3.2.a Singlering and double- or concentric-ring infiltrometers. In: J.H. Dane and G.C. Topp (co-eds.), Methods of soil analysis; Part 4, Physical methods; No. 5 in the Soil Science Society of America Book Series. Soil Science Society of America, Inc., Madison, WI, USA, pp 821-826.

Reynolds W.D., Vieira S.R., Topp G.C. 1992. An assessment of the single-head analysis for the constant head well permeametre. Can. J. Soil Sci. 72:489-501.

Reynolds W.D., Zebchuk W.D. 1996. Hydraulic conductivity in a clay soil: two measurement techniques and spatial characterisation. Soil Sci. Soc. Am. J. 60:1679-85.

Vauclin M., Elrick D.E., Thony J.L., Vachaud G., Revol Ph., Ruelle P. 1994. Hydraulic conductivity measurements of the spatial variability of a loamy soil. Soil Technol. 7:181-95.

Verbist K., Baetens J., Cornelis W.M., Gabriels D., Torres C., Soto G. 2009. Hydraulic conductivity as influenced by stoniness in degraded drylands of Chile. Soil Sci. Soc. Am. J. 73:471-84.

Verbist K., Torfs S., Cornelis W.M., Oyarzún R., Soto G., Gabriels D. 2010. Comparison of single- and double-ring infiltrometer methods on stony soils. Vadose Zone J. 9:462-75.

Verbist K.M.J., Cornelis W.M., Torfs S., Gabriels D. 2013. Comparing methods to determine hydraulic conductivities on stony soils. Soil Sci. Soc. Am. J. 77:25-42.

Warrick AW. 1998. Appendix 1: spatial variability. In: D. Hillel (ed.), Environmental soil physics. Academic Press, San Diego, CA, USA, pp 655-675.

White I., Sully M.J. 1992. On the variability and use of the hydraulic conductivity alpha parameter in stochastic treatments of unsaturated flow. Water Resour. Res. 28:209-13.

Wu L., Pan L., Mitchell J., Sanden B. 1999. Measuring saturated hydraulic conductivity using a generalised solution for singlering infiltrometers. Soil Sci. Soc. Am. J. 63:788-92.

Yitayew M., Khan A.A., Warrick A.W. 1998. In situ measurement of soil hydraulic conductivity using point application of water. Appl. Eng. Agric. 14:115-20.

Youngs E.G., 1987. Estimating hydraulic conductivity values from ring infiltrometer measurements. J. Soil Sci. 38:623-32. 